\title{
A CONCISE GUIDE TO DENTAL IMPLANTS
}

An iBook called A step by step guide for restoring dental implants, first edition, is available for download on your iPad with iBooks or on your computer with iTunes, at a cost of $£ 14.99$.

The book, which is written by $\mathrm{Dr}$ Martin Wanendeya and published by Ten Dental Publishing, is 22 pages long and offers dentists a good understanding of the stages involved in working with implants: treatment planning, surgery and restoration, so that you will be able to discuss your patients' implant options with confidence.
A regular

book

reviewer

for the $B D J$

reported

that it

was 'very

concise,

almost to the

point where it reminds me of a series of lecture slides'. It has also been given five out of five stars by two iTunes reviewers.

https://itunes.apple.com/gb/book/ step-by-step-guide-to-restoring/ id535279950? $\mathrm{mt}=11$

\section{TAKE VIVID IMAGES OF POSTERIOR TEETH}

The Digital Doc Iris from Digital Dental combines brilliance with beauty and is the latest advance in intraoral cameras because it is simpler, smarter and sharper.

The high quality IRIS digital intraoral camera enables dentists to communicate better to increase acceptance for their treatment plans. Simply use the 5-point Focus Wheel for superb crystal clear high magnification intraoral images.

Similarly, its small soft-tip, with brilliant automatic 8-point LED lighting, makes it even easier to take good close up images of posterior teeth. Combined with the new bright Glo True Spectrum LED light it also enables clinicians to quickly capture full face, full smile, upper and lower arch shots in sparkling colour and sharp detail.

The robust and easily portable Iris is no bigger than an electric toothbrush and fits any PC. It can also be fitted to any dental unit and integrates with any dental imaging software. Combine the camera with a ceiling mounted display for the perfect patient communication and entertainment system.

Digital Dental has installed over a thousand of these systems, so can demonstrate how to quickly and easily use IRIS to get the best images possible and a speedy return on investment.

For further information call 0800 0278393 or visit www.digitaldental. co.uk.

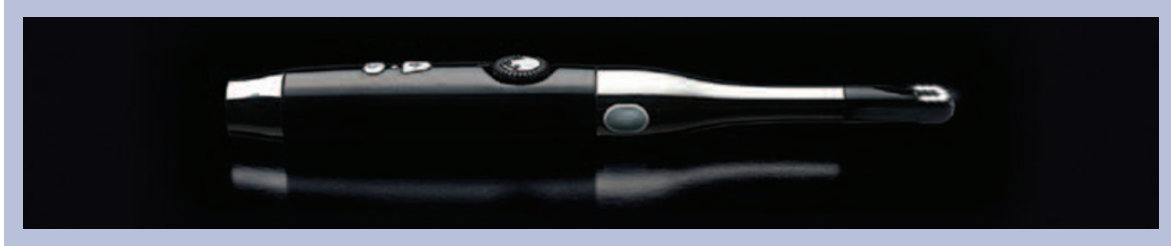

\section{THE MATERIAL OF CHOICE}

Featuring DMG's patented Honigum Technology, Honigum-Mixstar Heavy contains a unique microcrystalline wax matrix. This rheologically active matrix combines with its unique 'Directed Flow' characteristic to facilitate unprecedented flow even in problem areas. Together they offer the benefits of exceptional precision, exact margin reproduction, thixotropic nondripping consistency, easy removal, distortion free storage, neutral taste and honey scent.

For further information call DMG Dental Products on 01656 789401, email info@dmg-dental.co.uk or visit www.dmg-dental.com. 